\title{
Some effects of a buzzer CS and a novel buzzer on self-punitive running in rats
}

\author{
BRIAN M. KRUGER, MICHAEL J. WIETZEL, and PATRICK E. CAMPBELL \\ Wright State University, Dayton, Ohio 45435
}

\begin{abstract}
Self-punitive behavior was demonstrated in prepunishment speeds during extinction following shock escape training in a straight runway under buzzer-CS and under no-CS conditions. The buzzer enhanced punished running (shock in the last half of the runway) and nonpunished running. The buzzer did not significantly enhance self-punitive behavior, defined as the difference between punishment conditions with faster running for punished rats than for nonpunished rats. Introduction of a novel buzzer at the beginning of extinction enhanced both punished and nonpunished running relative to no-CS conditions but had no effect on selfpunitive behavior. Discontinuance of the buzzer CS at the end of acquisition eliminated selfpunitive behavior during extinction. The results were interpreted as supporting explanations of self-punitive behavior in terms of fear conditioning and conflict resolution.
\end{abstract}

Facilitative effects of self-administered punishment between the startbox and goalbox during extinction following electric shock escape training in an alley have been reported by many investigators (see Brown, 1969; Melvin, 1971, for reviews). Mowrer's (1947) explanation for the observed enhancement of running speeds and/or increased resistance to extinction relative to nonpunished controls has emphasized fear conditioned in the startbox during acquisition. According to this view, self-punitive running is maintained by the startbox fear that motivates running. The fear is maintained by the temporally delayed onset of shock in the alley, and running is further reinforced and maintained by the reduction of fear that occurs upon entering the distinctively different goalbox. For nonpunished controls, the absence of shock leads to the extinction of fear and the extinction of the running response. Self-punitive behavior has been demonstrated when self-punitive running is maintained better than nonpunished running.

In many self-punitive behavior experiments, an auditory stimulus of a buzzer has been added to the startbox stimulus complex. Typically, when used, the buzzer is turned on a few seconds prior to the start of each trial, thus establishing conditions for conditioning of fear to the buzzer. The buzzer is turned off as the rat enters the goalbox; thus all fear-eliciting stimuli are terminated at the same time. According to a fear conditioning view, such as Mowrer's, the addition of a salient conditioned stimulus (CS), such as a buzzer, should enhance both punished and nonpunished performances.

The data reported were collected by the second author in partial fulfillment of the requirements of the departmental honors program. Requests for reprints of this report and/or copies of a version including a second phase of extinction should be sent to Brian M. Kruger, Department of Psychology, Wright State University, Dayton, Ohio 45435.
However, it is not clear whether self-punitive behavior, defined as the difference between group performances with greater persistence or stronger responding under self-punishment conditions, should be affected.

The frequent addition of a buzzer CS in self-punitive studies has been questioned by Delude (1973). He suggested that a buzzer may not be an initially neutral stimulus and implied that running during extinction may be maintained by unconditioned properties of the buzzer rather than by elicitation of conditioned fear. $\mathrm{He}$ also implied that self-punitive behavior may be enhanced, although he did not indicate how the unconditioned properties of a buzzer might favor self-punished running relative to nonpunished running. Clearly, both punished and nonpunished running might be enhanced without affecting self-punitive behavior.

Delude (1973), in support of his hypothesis, cited a report of better avoidance conditioning with a buzzer than with a tone (Myers, 1962). Recently, Kruger and Campbell (1980) reported that a buzzer CS does enhance punished and nonpunished running relative to a tone CS but does not significantly enhance self-punitive behavior. Thus, their results do not support the view that self-punitive behavior is uniquely affected by the use of a buzzer CS.

Kruger and Campbell's (1980) results do not, however, answer a related question of whether the use of a buzzer CS throughout training and extinction (in addition to the usual apparatus stimuli) might differentially affect self-punitive behavior when compared with no-CS conditions throughout training and extinction. The present experiment was designed to make this comparison and to make other related manipulations.

One additional manipulation was to discontinue the use of the buzzer CS following training. From a fear conditioning view, this procedure should reduce running during extinction. Another manipulation was to intro- 
duce a novel buzzer during extinction. This procedure would permit some additional assessment of the effects of the unconditioned properties of the buzzer in the relative absence of fear conditioning. (Fear may be directly conditioned to the buzzer during extinction under punishment conditions and conditioned through second-order conditioning under both punished and nonpunished conditions.) It is not clear whether selfpunitive behavior should be differentially affected by either of these additional conditions relative to the no-CS condition.

\section{METHOD}

\section{Subjects}

Sixty-four male albino rats of Sprague-Dawley descent from the colony maintained by the Department of Psychology at Wright State University were used. The animals ranged in age from 115 to 175 days. All were individually caged and maintained with free access to water and Purina Laboratory Chow on a 14h-light, 10h-dark cycle. All rats were run during dark phases.

\section{Apparatus}

Details of the apparatus have been described elsewhere (Kruger \& Campbell, 1980). It consisted of a grid-floored runway $(122 \times 10.2 \times 20.3 \mathrm{~cm})$ and lower startbox $(30.5 \times 10.2 \mathrm{~cm})$, an upper trapdoor-floored startbox, and a large solid-floored goalbox. The upper startbox was gray with a white lid and offset ceiling light for orienting toward the alley. The lower startbox and alley had clear tops and translucent white plastic walls and subfloors below the grids. Light from below the alley and startbox provided diffuse illumination through the plastic. The goalbox lid was black except for a dim light source, and the walls and floor were painted in a black-and-white checkerboard pattern. For shaping trials the upper startbox could be placed over the alley adjacent to the goalbox or at a distance of $61 \mathrm{~cm}$ from the goalbox. Running speeds accurate to $.01 \mathrm{sec}$ were recorded for the two $61-\mathrm{cm}$ segments of the alley with the use of photocells and infrared sources located at the beginning, middle, and end of the alley. Starting speeds were measured from trapdoor release to interruption of the first infrared beam. The output lines of the $70-\mathrm{V}$ ac shock source were connected to alternate grid bars with a $10-\mathrm{kohm}$ resistor connected in series with the grid. The apparatus was located in a sound-reduction room with a white-noise sound source. A buzzer mounted externally on the rear wall of the upper startbox raised the sound level from a $72-\mathrm{dB}$ background to $93 \mathrm{~dB}$ when activated. The room was dark except for ambient light from the apparatus.

\section{Procedure}

Fifteen trials were administered in acquisition, with shock present throughout the grid areas. On each trial the rat was placed in the upper startbox and dropped after a 10 -sec delay. For a random half of the rats, onset of the buzzer occurred $2 \mathrm{sec}$ before the drop; for the other half, no buzzer was presented. Unseen by the rats through the opaque trapdoor, the lights for the lower startbox and alley were turned on $2 \mathrm{sec}$ before the drop on all trials in all phases. These lights and the buzzer, if present, were terminated when the door to the goalbox began to close. The subject remained in the goalbox for $40 \mathrm{sec}$ after door closure. The end of this interval was signaled to the experimenter by a small lamp. Approximately $10 \mathrm{sec}$ elapsed in removing the rat from the goalbox, placing it in the upper startbox, and pressing a switch to begin the $10 \mathrm{sec}$ delay. This interval completed the 60 -sec interval from goalbox door closure to drop. The upper startbox was placed adjacent to the goalbox for the first two trials and $61 \mathrm{~cm}$ from the goalbox for the next three trials. Speed measures were not taken during these five shaping trials. The remaining 10 trials were with the full length of the alley.

Trials during extinction were administered with essentially the same procedures as used in acquisition. For nonpunished trials there was no shock in the startbox or alley. For punished trials there was shock in the last $61-\mathrm{cm}$ section of the alley but not in the first alley segment or in the lower startbox.

On each extinction trial, if the rat did not enter the goalbox within $30 \mathrm{sec}$ after the drop, the rat was removed from the alley or startbox and placed in the goalbox for the $40 \mathrm{sec}$ goalbox confinement interval. Trials in extinction were terminated after four successive failures to leave the startbox within $30 \mathrm{sec}$ or after 80 trials. Arbitrary times of $30 \mathrm{sec}$ were entered for all measures not obtained on criterial or precriterial trials and for all trials not actually run.

During extinction, rats within each acquisition condition, buzzer and no buzzer, were randomly assigned to four conditions defined by two factors. One factor was the presence or absence of the buzzer CS; the other was the presence or absence of shock in the $61 \mathrm{~cm}$ alley segment adjacent to the goalbox. Thus, a 2 by 2 by 2 factorial design with acquisition buzzer, extinction buzzer, and extinction punishment (shock) factors was employed. Three letters, one for each factor, identify each group; a hyphen separates the second and third letters. The first two letters represent the buzzer conditions for acquisition and extinction, respectively ( $\mathrm{B}=$ buzzer, $\mathrm{N}=$ no buzzer); the third refers to punished $(\mathrm{P})$ or nonpunished $(\mathrm{N})$ conditions in extinction.

\section{RESULTS}

\section{Acquisition}

None of the three speed measures taken during acquisition (see Figures 1 and 2) was significantly affected by the buzzer-CS vs. no-buzzer variable. There were no statistically significant differences among any of the eight groups on the final block of acquisition.

\section{Extinction}

Extinction performances are also shown in Figures 1 and 2 . The numbers near extinction starting-speed data points in these figures indicate the number of rats that did not meet the extinction criterion and that ran at least one trial within the block. All groups had eight rats at the beginning of extinction.

The extinction results for the continuous buzzer-CS groups (BB-N and BB-P) are shown in Figure 1. There was no significant difference in starting speeds, but punished rats ran significantly faster in the first-segment prepunishment area during the last five blocks $[F(1,56)=18.55, p<.001]$ and ran faster in the punishment area $[F(1,56)=13.74, p<.001]$.

The results for groups never experiencing the buzzer during acquisition or extinction (NN-N and NN-P) are shown in Figure 2. The nonpunished (NN-N) rats started faster than the punished (NN-P) rats $[\mathrm{F}(1,56)=8.56$, $\mathrm{p}<.01]$, but they ran slower in the prepunishment area $[F(1,56)=4.98, p<.05]$ for the last five blocks, and slower in the punishment area $[\mathrm{F}(1,56)=7.04$, $\mathrm{p}<.025]$. Thus, self-punitive behavior was demonstrated in the prepunishment area in the absence of the buzzer.

Some comparisons were made among continuous buzzer groups and continuous no-buzzer groups; these 
are shown separately in Figures 1 and 2. On the last five blocks the BB-P group was faster than the NN-P group $[F(1,56)=34.09, p<.001]$, and the BB-N group was faster than the NN-N group $[\mathrm{F}(1,56)=14.16$, $p<.001]$. The magnitude of the self-punitive effect in prepunishment speeds, as assessed for the last five blocks, was not significantly different for buzzer than for no-buzzer conditions $[F(1,56)=2.15, \mathrm{p}>.10]$. Results for these groups were essentially the same for second-segment speeds, except that the magnitudes of the self-punitive effect, as assessed on the last five blocks, were significantly different $[F(1,56)=8.35$, $\mathrm{p}<.01$ ], with a greater difference between punished and nonpunished groups under buzzer conditions than under no-buzzer conditions.

As shown in Figure 1, discontinuance of the buzzer during extinction eliminated the self-punitive effect, with the nonpunished group (BN-N) generally starting and running faster than the punished group (BN-P) for all measures. Removal of the buzzer resulted in faster starting speeds than continuation of the buzzer under

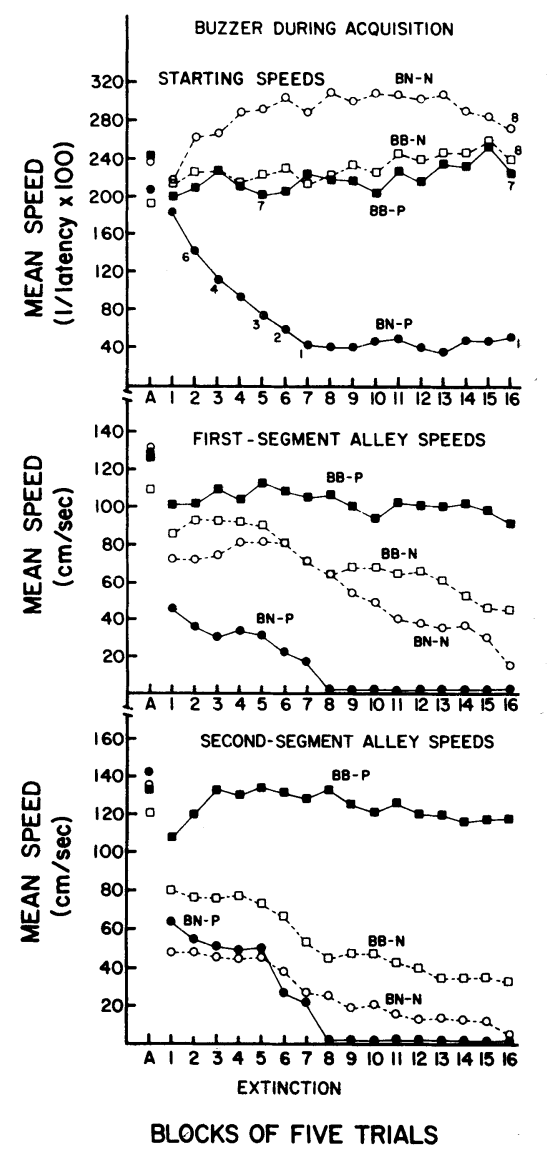

Figure 1. Mean speeds for the last block of acquisition and 16 blocks of extinction for groups given acquisition with a buzzer CS.

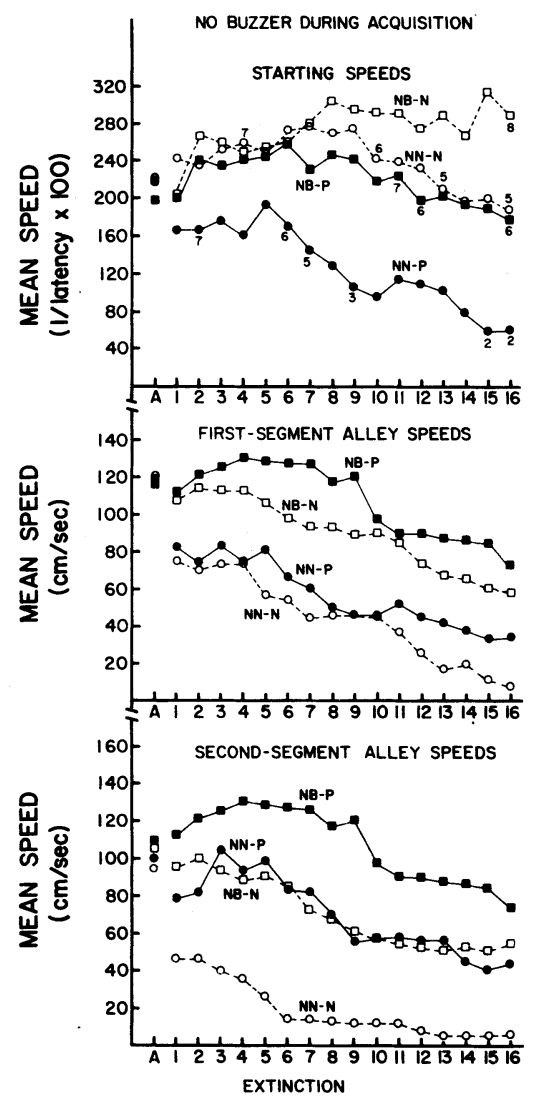

BLOCKS OF FIVE TRIALS

Figure 2. Mean speeds for the last block of acquisition and 16 blocks of extinction for groups given acquisition without a buzzer CS.

nonpunishment conditions [(BN-N vs. BB-N for the last five blocks), $\mathrm{F}(1,56)=4.61, \mathrm{p}<.05]$.

As shown in Figure 2, the introduction of a novel buzzer in extinction produced results similar to the results for no-buzzer groups. The nonpunished (NB-N) rats started faster than punished (NB-P) rats $[F(1,56)=$ 19.97, $\mathrm{p}<.001$ (for the last five blocks)], but they ran slower in the punishment area than the punished rats $[F(1,56)=12.49, p<.005]$. However, the selfpunitive behavior indicated by faster running in the prepunishment area by punished rats only approached significance for the last five blocks $[F(1,56)=3.71$, $\mathrm{p}<.10]$. The magnitude of self-punitive behavior in prepunishment speeds and in punishment-area speeds, as assessed on the last five blocks, did not differ significantly from the magnitude of self-punitive behavior under no-buzzer conditions or under continuous buzzer conditions $[F(1,56)=2.83, \mathrm{p}>.05$, for each test $]$.

Again, as when the BN-N and BB-N groups were compared, a shift in buzzer conditions from acquisition to extinction enhanced starting speeds. The NB-N rats started faster than the NN-N rats $[\mathrm{F}(1,56)=15.27$, 
$\mathrm{p}<.001$, for the last five blocks]. Indeed, except for the BN-N and BB-N comparison in extinction starting speeds, the presence of the buzzer enhanced all speed measures during extinction when comparisons are made within like punishment conditions (see Figures 1 and 2).

\section{DISCUSSION}

The extinction results for continuous buzzer and continuous no-buzzer groups were essentially the same as for buzzer and tone groups, respectively, reported by Kruger and Campbell (1980). Self-punitive behavior was demonstrated in prepunishment area speeds for both buzzer and nobuzzer conditions, but the magnitude of the self-punitive effect in prepunishment speeds was not significantly different for buzzer and no-buzzer conditions. These results do not support the view that selfpunitive behavior in prepunishment speeds is produced or affected by the use of a buzzer CS.

The present study did find a greater self-punitive effect under buzzer-CS than under no-buzzer conditions for punishment area speeds. These results are similar to the findings of Eaton and Crowell (1977) for a two-way automated apparatus. They reported that the self-punitive effect as measured by differences in the number of trials to extinction was significantly enhanced by a buzzer compared with no buzzer. However, their nonpunished no-buzzer rats on the average ran fewer than three trials in extinction; in the present study, nonpunished nobuzzer rats ran very slowly in the second segment for the last five blocks for which the interaction was evaluated. Thus, these differential results may be attributable to floor effects of the measures rather than to genuine effects of a buzzer.

Introduction of a novel buzzer enhanced both punished and nonpunished starting and running when introduced in extinction. These results are quite different from the results of Delprato and Carosio (1976) for a novel tone. They found that a novel tone did not enhance either punished or nonpunished running and eliminated the self-punitive effect observed under no-tone conditions. Myers (1962), in discussing reasons for poorer avoidance performance with a tone CS than with a buzzer CS, cited evidence (Myers, 1959) that poorer performance with the tone may be due in part to elicitation of freezing by the tone and elicitation of startle by the buzzer. In the present situation, as in avoidance training, freezing would be incompatible with starting and running, whereas startle and activity could be compatible with and facilitate starting and running. Another possible explanation (Myers, 1962) of better performance under buzzer than tone conditions, which seems potentially applicable to the present comparison of results, is that the buzzer may be more similar to shock than the tone; thus responses conditioned to shock should generalize to a novel buzzer more readily than to a novel tone, and responding should be better with a buzzer.

The relatively rapid reduction or elimination of starting and running by punished rats shifted from buzzer conditions in acquisition to no buzzer in extinction may be due to stimulus change (stimulus generalization decrement) and/or to removal of the fear that was classically conditioned to the buzzer and/or startbox stimuli during acquisition. However, since performance was enhanced under novel buzzer conditions (stimulus change of no buzzer to buzzer), stimulus generalization decrement may be relatively unimportant.

Although the data presented here support the view that a buzzer has unconditioned properties that will enhance punished and nonpunished running, the major findings concerning selfpunitive behavior are compatible with a fear-conditioning interpretation, such as Mowrer's (1947) view, that appeals to conditioning and maintenance of fear to startbox stimuli. However, certain aspects of the results may more adequately be explained by the suggestion that conflict is introduced by direct conditioning of fear to alley cues during punished extinction (Delude, 1973; Kruger, 1974). For example, slower starting speeds, but faster prepunishment speeds for punished than for nonpunished rats, as observed under no-CS conditions, suggest that starting may be slower due to conflict. A conflict-resolution interpretation would also seem to more adequately explain the basic fact that some punished rats do extinguish running (Delude, 1973).

\section{REFERENCES}

Brown, J. S. Factors affecting self-punitive locomotor behavior. In B. A. Campbell \& R. M. Church (Eds.), Punishment and aversive behavior. New York: Appleton-Century-Crofts, 1969.

Delprato, D. J., \& Carosio, L. A. Elimination of self-punitive behavior with a novel stimulus and safety signal. Animal Learning \& Behavior, 1976, 4, 210-212.

Delude, L. A. Factors affecting the strength of the vicious circle phenomenon. Psychological Record, 1973, 23, 467-476.

Eaton, N. K., \& Crowell, C. R. Two-way self-punitive locomotor behavior. Bulletin of the Psychonomic Society, 1977, 9, 73-76.

Kruger, B. M. Self-punitive running in the rat following start box fear conditioning: Shock intensity effects. Journal of Comparative and Physiological Psychology, 1974, 87, 555-562.

Kruger, B. M., \& Campbell, P. E. Some effects of type of auditory CS on self-punitive running in rats. Bulletin of the Psychonomic Society, 1980, 15, 51-53.

Melvin, K. B. Vicious circle behavior. In H. D. Kimmel (Ed.), Experimental psychopathology: Recent research and theory. New York: Academic Press, 1971.

Mowner, O. H. On the dual nature of learning-A reinterpretation of "conditioning" and "problem solving." Harvard Educational Review, 1947, 17, 102-148.

Myers, A. K. Avoidance learning as a function of several training conditions and strain differences in rats. Journal of Comparative and Physiological Psychology, 1959, 52, 381-386.

MYers, A. K. Effects of CS intensity and quality in avoidance conditioning. Journal of Comparative and Physiological Psychology, 1962, 55, 57-61.

(Received for publication January 30, 1980.) 